\title{
Video Article \\ Additive Manufacturing of Functionally Graded Ceramic Materials by Stereolithography
}

\author{
Pablo Gonzalez ${ }^{*}$, Eric Schwarzer ${ }^{{ }^{2}}$, Uwe Scheithauer ${ }^{2}$, Norbertus Kooijmans ${ }^{1}$, Tassilo Moritz ${ }^{2}$ \\ ${ }^{1}$ Admatec Europe B.V. \\ ${ }^{2}$ Fraunhofer Institute for Ceramic Technology and Systems IKTS Dresden \\ *These authors contributed equally
}

Correspondence to: Uwe Scheithauer at Uwe.Scheithauer@ikts.fraunhofer.de

URL: https://www.jove.com/video/57943

DOI: doi:10.3791/57943

Keywords: Engineering, Issue 143, Ceramics, additive manufacturing, digital light processing, photopolymer, stereolithography, suspension viscosity, multi-material, dense-porous, pore-gradient

Date Published: 1/25/2019

Citation: Gonzalez, P., Schwarzer, E., Scheithauer, U., Kooijmans, N., Moritz, T. Additive Manufacturing of Functionally Graded Ceramic Materials by Stereolithography. J. Vis. Exp. (143), e57943, doi:10.3791/57943 (2019).

\section{Abstract}

An additive manufacturing technology is applied to obtain functionally graded ceramic parts. This technology, based on digital light processing/ stereolithography, is developed within the scope of the CerAMfacturing European research project. A three-dimensional (3-D) hemi-maxillary bone-like structure is 3-D printed using custom aluminum oxide polymeric mixtures. The powders and mixtures are fully analyzed in terms of rheological behavior in order to ensure proper material handling during the printing process. The possibility to print functionally graded materials using the Admaflex technology is explained in this document. Field-emission scanning electron microscopy (FESEM) show that the sintered aluminum oxide ceramic part has a porosity lower than $1 \%$ and no remainder of the original layered structure is found after analysis.

\section{Video Link}

The video component of this article can be found at https://www.jove.com/video/57943/

\section{Introduction}

High-complex technical ceramics are increasingly in demand in almost every field of application, including many industrial areas. The field of human healthcare finds more and more applications as a result of the ease of individualization of the products for each patient. In the last decade, additive manufacturing has enhanced the options of individual medical treatments.

Additive manufacturing (AM) is a processing technology that allows the translation of a computer-generated 3-D model into a physical product by sequenced addition of material. In general, a series of 2-D layers form a stack that results in a 3-D shape, allowing the production of components with a, so far, unprecedented freedom of design. This is considered to be state-of-the-art shaping technology for polymers and metals. The first industrial technologies for ceramic processing are available ${ }^{1,2}$, and nearly all known AM technologies are used for AM of single-material ceramics in laboratories all over the world ${ }^{3,4,5}$. AM, especially stereolithography, began in the 1980 s and was developed by Hull ${ }^{6}$. Different manufacturing approaches and materials lead to a variety of product properties, such as size, roughness, or mechanical properties. All additive manufacturing techniques can be classified into two groups: direct additive manufacturing technologies ${ }^{5}$, which are based on the selective deposition of the material (e.g., material jetting processes like Direct Inkjet Printing or Thermoplastic 3-D Printing [T3DP]) $)^{7,8,9,10}$, and indirect additive manufacturing technologies, which are based on the selective consolidation of the material which is deposited on the whole layer (e.g., ceramic stereolithography [SLA]).

The complexity and readiness of the new applications demand an improvement of the AM ceramic processing technologies. For example, special innovative industrial or medical applications have to include different properties within the very same component, which leads to Functionally Graded Materials (FGMs). These materials include a variety of properties concerning transitions in the microstructure or in the material ${ }^{11}$. These transitions can be discrete or continuous. Different kinds of FGMs are known, such as components with material gradients or graded porosity, as well as multi-colored components. FGM components can be manufactured by single conventional shaping technologies $^{12,13,14,15,16,17}$ or by a combination of these technologies, for example, by in-mold labeling as a combination of tape casting and injection molding ${ }^{18,19}$.

To combine the benefits of AM with the advantages of FGMs to ceramic-based 4-D components ${ }^{20}$ (three dimensions for the geometry and one degree of freedom concerning the material properties at each position), Admatec Europe has developed a stereolithography-based 3-D printing device within the "CerAMfacturing" European research project for the AM of multi-functional or multi-material components.

The technology adapted for FGM components is a stereolithography-based approach that employs a digital light processor (DLP) as light source containing a digital micromirror device chip (DMD), used to polymerize a resin which can be mixed with different powders. The DMD chip has an array of several hundred thousand microscopic mirrors, which correspond to the pixels in the image to be displayed. The mirrors can be 
individually rotated to set an on-off position of the pixel. The most commonly employed resins are based on mixtures of acrylate and/or urethane monomers. In these mixtures, we also found other additives, such as light-absorbing photoinitiator molecules and dyes. The resin mixture is typically poured into a container or bath, also called vat. The polymerization is induced by the reaction of a photoinitiator molecule (PI), with the light photons generated by the DMD chip. Different resin monomer structures may result in different polymerization rates, shrinkage, and final structure. For example, the use of monofunctional monomers vs. polyfunctional monomers has an effect in the cross-linking of the polymeric network.

One of the most important parameters to take into account with ceramic SLA is the light-scattering effect produced when light (photons) traverses through different materials. This is highly impacting; in this case, the resins are combined with an amount of powder to generate a suspension or slurry. The slurry is, then, composed of materials that present a different refractive index to the light. A large difference between the refractive index values of the resin and the powder affects the dimensional accuracy of the layers, the polymerization rates, and the total light dose to trigger the polymerization reaction. When light enters the suspension, the powder particles (i.e., ceramic, metal, or other polymers) diffract the light path. This effect induces a change in the original path of the (irradiated) photons. If the photons have a trajectory oblique to the exposure direction, they may generate a polymerization reaction in a location that can be transversal to the original direction. This phenomenon results in overexposure when the area of the cured slurry is larger than the exposed area. Likewise, it will under-expose, when the cured slurry layer is smaller than the originally exposed area.

Within the manuscript, the research for the AM of alumina components combining a dense and macroporous structure, realized by using the Admaflex technology, is described. As explained in the "CerAMfacturing" European research project, the production of FGM ceramic parts requires a high resolution and good surface properties to meet the demanding applications. DLP stereolithographic technologies, such as the one described here, allows researchers to obtain such ceramic-based, fully functional components.

\section{Development of Photocurable Ceramic Suspensions}

\section{Selection of ceramic powders}

1. Use high-purity ceramic powders (e.g., aluminum oxide powder of $99.9 \%$ purity or higher).

2. Choose powders with (1) a narrow particle size distribution for poor viscosity, (2) a mean particle size of $<0.5 \mu \mathrm{m}$ for good sinterability, and (3) a specific surface in the vicinity of $7 \mathrm{~m}^{2} / \mathrm{g}$ for a low viscosity.

\section{Powder specification}

1. Characterize the powders concerning shape, surface area, and particle size distribution if needed (Table of Materials).

2. Characterize the particle shape using, for instance, FESEM analyses. In order to do so, take (a few milligrams) of powder with a spatula and deposit it on a carbon tape square with an area size of approximately $100 \mathrm{~mm}^{2}$. Metalize the ensemble prior to the introduction in the microscope chamber.

3. Assess the particle size distribution of the utilized powders with, for instance, a laser diffraction method. Put (a few milligrams) of the sample with a spatula into the mixing chamber of the machine and deagglomerate it using high-frequency ultrasound waves $5 x$ for 5 min each time.

4. Measure the specific surface properties of the used powders using the Brunauer-Emmet-Teller (BET) approach. Collect the adsorption/ desorption isotherms in liquid nitrogen. Degas the samples at $150^{\circ} \mathrm{C}$ prior to the measurements.

3. Selection of polymeric resin

1. Choose, for example, a monofunctional binder (1; see Table of Materials) together with a di(2)- and tetra(3)-functional crosslinker (see Table of Materials) and a photoinitiator (4; see Table of Materials) active in the wavelength of the used printing device's light engine, in this case at $405 \mathrm{~nm}$.

2. For a more flexible polymer network, use a plasticizing fluid (5; see Table of Materials).

\section{Preparation of ceramic suspensions}

1. If necessary, deagglomerate the alumina powders using a volatile solvent, such as ethanol absolute, together with a dispersing agent (see Table of Materials) and alumina milling balls.

1. For this, mix $80 \mathrm{wt} . \%$ of powder with $20 \mathrm{wt} . \%$ solvent together with the same absolute mass-like powder of mill balls with a diameter of $1-2 \mathrm{~mm}$, and add dispersing agent in a range of 0.5 to $2.0 \mathrm{wt} . \%$ based on the powder content.

2. Mill the mixture for $2 \mathrm{~h}$ in a planetary ball mill (see Table of Materials) to deagglomerate the powder in order to achieve the primary particle size.

3. After milling, separate the powder mass from the mill balls by using a sieve (with a mesh of $500 \mu \mathrm{m}$ ) and dry the suspension in a fume hood for $12 \mathrm{~h}$ at room temperature and, subsequently, in a stove dryer for $24 \mathrm{~h}$ at $110^{\circ} \mathrm{C}$.

4. Grind the dried powder through a sieve $(100-500 \mu \mathrm{m})$ to get the deagglomerated and functionalized powder. Note: The surface of the particles is now functionalized with the dispersing agent necessary for a stable and low-viscous suspension.

2. Adapt the properties of the developed suspensions, especially the dynamic viscosity, to the printing process. Here, four different compounds were prepared and characterized in terms of dynamic viscosity and their curing behavior. Four different compounds (I, II, III, and IV) were created by changing the compositions.

1. In compound I, use a ratio of 1.5 between the di- and tetra-functional crosslinkers. Use a ratio between the complete crosslinker and the monofunctional binder of 1.2. The content of the photoinitiator was $1.3 \mathrm{wt} . \%$ to the reactive resin, and the content of the plasticizer was $30 \mathrm{wt} . \%$ of the total. Within compound I, use a powder content of $78 \mathrm{wt} . \%$.

2. In compound II, increase the powder content to $82 \mathrm{wt} . \%$. 
3. In compound III, increase the amount of tetra-functional crosslinker by changing the ratio of the di- and tetra-functional crosslinkers to 1.8 .

4. In compound IV, reduce the powder content to $75 \mathrm{wt} . \%$ and change the ratio of the crosslinker to the monofunctional binder to 1.0 .

3. Mix the different organic and photoreactive components based on the compounds I to IV described in section 1.4.2. Introduce the components into a can of a high-speed planetary ball mill (see Table of Materials) and homogenize the mixture for 4 min at a speed of $1,000 \mathrm{rpm}$. Additionally, a plasticizer can be added to get a higher flexibility of the polymer after curing.

5. Adding powder into the polymer mixture

6. Homogenize the mixture at three levels: for $4 \mathrm{~min}$ at $1,000 \mathrm{rpm}$, for $45 \mathrm{~s}$ at $1,500 \mathrm{rpm}$, and for $30 \mathrm{~s}$ at $2,000 \mathrm{rpm}$. Note: In case of an increased temperature, cool down the can with water. If necessary, repeat the mixing a second time.

7. Characterization of the suspension

1. Characterize the rheological behavior, especially the dynamic viscosity as a characteristic value of the flow behavior. The measurement set-up should be based on the printing process parameters, especially the casting speed.

1. Use a rheometer with a cone/plate measuring system ( $25 \mathrm{~mm}$ in diameter), adjustable between $-25^{\circ} \mathrm{C}$ to $200{ }^{\circ} \mathrm{C}$ (see Table of Materials).

2. Put a sample (approximately $1 \mathrm{~mL}$ ) of the suspension on the plate and follow the measuring instructions of the rheometer for a rotational measurement.

3. Analyze the dynamic viscosity by increasing the shear rate of 0.01 to $1000 \mathrm{~s}^{-1}$ at a constant temperature of $20^{\circ} \mathrm{C}$ and measuring the torque.

Note: During the process, the suspension is cast with a velocity of $40 \mathrm{~mm} / \mathrm{s}$. Therefore, the shear rate is approximately $200 \mathrm{~s}^{-1}$, lower for the movement of the printed component, and fixed at the building platform, within the coated suspension. Consequently, the set-up of the rheological measurement is defined.

4. Make sure that the suspension shows a shear thinning behavior with a dynamic viscosity below $600 \mathrm{~Pa} \cdot \mathrm{s}$ for a shear rate of 0.1 $\mathrm{s}^{-1}$ and below $10 \mathrm{~Pa} \cdot \mathrm{s}$ for shear rates of 10 to $300 \mathrm{~s}^{-1}$.

2. Characterize the curing behavior of the developed suspensions. Analyze the curing behavior by oscillating measurements before, during, and after exposure with light (with a wavelength of 300 to $500 \mathrm{~nm}$ ).

1. Use a rheometer (see Table of Materials), e.g., adjustable between $-25^{\circ} \mathrm{C}$ to $200{ }^{\circ} \mathrm{C}$, with a plate/(glass)plate measuring system ( $25 \mathrm{~mm}$ in diameter) with a gap of $50 \mu \mathrm{m}$, in combination with a blue LED light source (with a wavelength of $405 \mathrm{~nm}$ ).

2. Fix the LED below the (glass) plate and adjust the intensity conform to the printing intensity (approximately $33 \mathrm{~mW} / \mathrm{cm}^{2}$ ) by using a photometer.

3. Put a suspension sample of approximately $1 \mathrm{~mL}$ onto the (glass) plate and move the plate of the measurement system to the measurement position using a gap of $50 \mu \mathrm{m}$.

4. Measure the storage modulus $\mathrm{G}^{\prime}$-a part of the complex shear modulus $\mathrm{G}^{*}$-by using a constant deformation amplitude (e.g. $\left.0.1 \%\left[0.09^{\circ}\right]\right)$ with a frequency of $10 \mathrm{rad} / \mathrm{s}$.

5. Before exposure, measure $\mathrm{G}^{\prime}$ in $10 \mathrm{~s}$ intervals for $60 \mathrm{~s}$. This represents a first plateau of $\mathrm{G}^{\prime}$ for the liquid suspension.

6. Once completed, start the exposure after $60 \mathrm{~s}$ by using the blue LED (see Table of Materials) for a defined duration (e.g., 1 $4 \mathrm{~s})$. Measure $\mathrm{G}^{\prime}$ during and after the exposure. $\mathrm{G}^{\prime}$ increases due to the exposure, which indicates the polymerization process. Depending on the exposure time and suspension properties, $G^{\prime}$ will increase to a second plateau during the polymerization.

\section{Manufacturing of Single-graded and FGM Components by Ceramic SLA}

1. Use a ceramic DLP-SLA printing device. See Discussion for the apparatus description.

1. Investigate the depth of the curing. This step is necessary to determine the curing capabilities of the slurry (i.e., the penetration depth of the light and the subsequent polymerization process). For this:

1. Apply approximately $1 \mathrm{~mL}$ of the ceramic-filled resin slurry (prepared in step 1.4) on a piece of transparent foil (see Discussion) with the help of a spatula. Use a polymer spatula that has a high chemical resistance (e.g., a nylon-glass fiber spatula).

2. Place the foil with the slurry flush on the printing glass plate.

3. Project, with the DLP-SLA printing device, a light masked test exposure for a fixed number of seconds in a range of 0.5 to $4 \mathrm{~s}$.

4. Remove the excess uncured slurry.

5. Measure the cured layer with the help of a micrometer. The cured thickness must be at least the same as that of the chosen building layers, although it is recommended to reach several times the thickness of the layer in order to provide enough light penetration.

6. Repeat steps 2.1.1.1. to 2.1.1.5 until the desired cured thickness is reached.

2. Manufacture the functionally graded material parts as follows.

1. Generate a 3-D model of the desired part using CAD software.

2. Slice the 3-D file to layers of the required thickness with the help of a slicing software. Typical layer thickness of the printing system ranges from 25 to $100 \mu \mathrm{m}$. Save the sliced file in *.slc format.

3. Transfer the *.slc file to the device via USB or network connection.

4. Create a printing program and adjust the printing parameters (e.g., curing time per layer, transport speed [casting speed], and building platform speeds).

5. Fill the reservoir of the printing device to half its capacity with the ceramic slurry (approximately $200 \mathrm{~g}$ ).

6. Transport the slurry to fill the pump system until the slurry starts to be pumped back into the reservoir. Make sure that the generated slurry layer is several times thicker as the targeted file slice layer thickness. 
7. Attach a printing metal plate to the building platform using vacuum pressure from the vacuum pump integrated into the printing device.

8. Start the printing program.

Note: The printing device will automatically transport the slurry layer. Refill the slurry reservoir during printing if necessary.

9. When the printing program is complete, remove the printing metal plate with the product. Switch off the vacuum pump and hold the plate at the same time.

10. Clean the remaining slurry attached to the product surface with a mild organic solvent (e.g., isopropanol). A thin layer of slurry may remain adhered to the surface of the parts, accentuated with products with a large surface.

11. Dry the rinsed products at room temperature under a fume hood.

\section{Co-debinding and Co-sintering of Single-graded and FGM Components}

1. Debind the green samples as described in the following steps.

1. First, put the samples on a special kiln furniture which was sintered at a temperature at least $50{ }^{\circ} \mathrm{C}$ higher than the final sintering temperature of the printed components. By doing this, transferring the debound components to another kiln furniture is not necessary.

2. Perform a debinding program with a low heating rate in a furnace (see Table of Materials) under air atmosphere up to $600{ }^{\circ} \mathrm{C}(e . g$., with a heating rate of $7.5^{\circ} \mathrm{C} / \mathrm{h}$ ). Use a dwell time at $200{ }^{\circ} \mathrm{C}, 400{ }^{\circ} \mathrm{C}$, and $600{ }^{\circ} \mathrm{C}$ of $10 \mathrm{~h}$. Increase the heating rate at $600{ }^{\circ} \mathrm{C}$ to $60^{\circ} \mathrm{C} / \mathrm{h}$ up to $900{ }^{\circ} \mathrm{C}$ and use a dwell of $2 \mathrm{~h}$. Cool down with a rate of $3-5^{\circ} \mathrm{C} / \mathrm{min}$.

Note: This cycle is based on prior characterization by TGA-DSC; however, a different set of polymer resin composition will require an updated debinding program. This is a crucial step in ceramic manufacturing and should not be ignored.

Note: All organic binder materials are, at this stage, thermally removed, while in the same step a presintering of the alumina particles is initiated to safely enable the subsequent transfer of the samples to a sintering kiln.

3. Transfer the samples with the carrier plate to a sintering furnace (see Table of Materials).

4. Sinter the samples under air atmosphere at $1,600{ }^{\circ} \mathrm{C}$ for $2 \mathrm{~h}$ in the furnace. Use a heating rate of $3^{\circ} \mathrm{C} / \mathrm{min}$ up to $900{ }^{\circ} \mathrm{C}$, followed by 1 ${ }^{\circ} \mathrm{C} / \mathrm{min}$ up to the final temperature of $1,600{ }^{\circ} \mathrm{C}$.

Note: The expected linear shrinkage of the components is about $20 \%-25 \%$ in the $x, y$-direction and $25 \%-30 \%$ in the $z$-direction.

\section{Characterization of Single-graded and Functionally Graded Components}

1. Cut the samples with a diamond saw and polish the surface using ceramographic methods.

1. Investigate the microstructure by using FESEM (see Table of Materials).

Note: Visually inspect the porosity of the two functionally graded phases and at the boundary interface of the used materials. To obtain a more detailed result, perform an interface analysis. If the porosity is too high, optimize the suspension composition (section 1), the printing parameters (section 2.2) and/or the thermal treatment (section 3 ). The targeted porosity is below $1 \%$.

\section{Representative Results}

For the production of single-material components and, eventually, functionally graded structures by means of a combination of dense and porous sections in a macroscopic range, only suspensions based on the alumina have been used.

The measurement result of the average particle diameter $\left(D_{50}\right)$ of the used alumina powder after dispersion was $0.47 \mu \mathrm{m}$. This result correlates with the given information of an actual particle size of 0.45 to $0.5 \mu \mathrm{m}$ from the supplier. Figure $1 \mathrm{~A}$ shows the FESEM analysis of the alumina powder before preparation and Figure 1B a FESEM image of a granulate surface in detail. Figure 1C and Figure 1D show the same for the deagglomerated alumina in a dried state. The untreated powders are not present as single primary particles, but as big spherical granules (with a diameter up to $100 \mu \mathrm{m}$ ), which is a typical condition for dry pressing raw materials. The FESEM images of the granulate surfaces show the primary particles of the alumina untreated (Figure 1B) and deagglomerated (Figure 1D) with an actual particle size of approximately $0.45 \mu \mathrm{m}$.

Figure 2 shows the dynamic viscosity of the developed suspensions based on the alumina powder as a function of the shear rate-logarithmic presentation-and depending on different compositions concerning varied powder content, binder-crosslinker ratio, and content of the dispersing agent. All suspension compositions show a shear thinning behavior, but different levels of dynamic viscosities.

The suspension homogeneity is shown in Figure 3 with a FESEM image of a thin slice of ceramic-polymeric resin. The ceramic primary particles appear clearly while the polymeric resin is to some extent not detected by the electron detector.

The measurement of the storage modulus $\mathrm{G}^{\prime}$ as a function of time to characterize the curing behavior as depending on time is shown in Figure 4. The adjustable parameter of the printing device helps to evaluate the curing time during printing. Generally, the suspension shows a constant level of $\mathrm{G}^{\prime}$ below 1,000 Pa for a steady deformation. During the exposure of the suspensions, which starts after $60 \mathrm{~s}, \mathrm{G}^{\prime}$ increases depending on the exposure time-varied in a range of 1 to $20 \mathrm{~s}$ - to a higher level of $\mathrm{G}^{\prime}$, above $10^{5} \mathrm{~Pa}$. Within the diagram, the curves represent different exposure times of a suspension to show the influence on the strength of the cured polymer-ceramic-composite.

The ceramic SLA printing equipment, using the Admaflex technology, can handle high viscosity ceramic slurries thanks to the transport system. The FGM parts can be conceived by a pixel-by-pixel control that directs the irradiated light for each section of the network. The under- and overexposure effects can be compensated for by the same pixel-by-pixel control feature. In addition, this is complemented by a developed software suite identifying the different sections-porous and dense-in order to compensate the light behavior differences per exposed area. This proprietary technology provides adapted light-curing strategies to such sections. 
By using a suspension with the dynamic viscosity behavior as presented in composition 1 (Figure 2), single-component FGMs with 3-D structures were manufactured after the empirical determination of the device parameters. Figure 5A shows a complex 3-D model and Figure 5B shows the sintered test structure based on the alumina suspensions additively manufactured within the research program.

Figure 6 shows FESEM images of the microstructure of a single-material FGM component within the dense part; the porosity is in a macroscopic range.
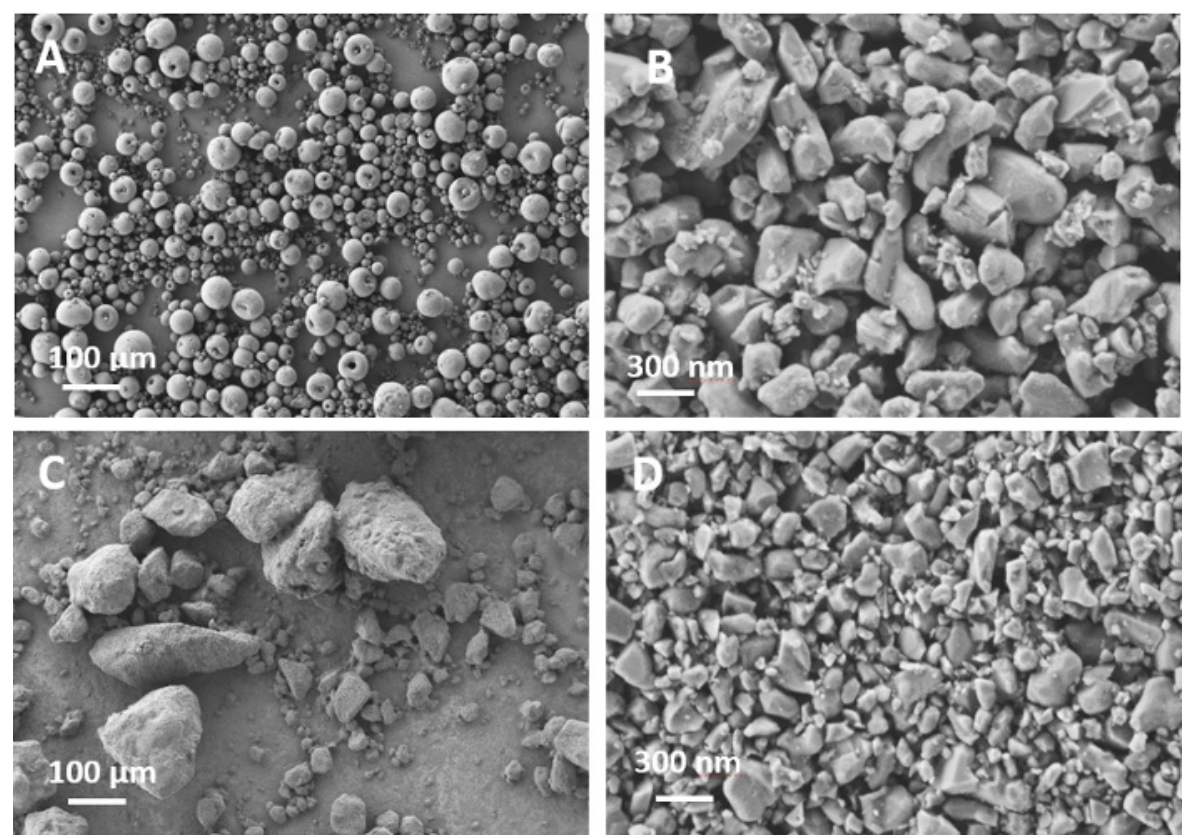

Figure 1: FESEM Images. The first two panels show field-emission scanning electron microscope images of (A) the original alumina powder and (B) surface detail. The next two panels show field-emission scanning microscope images of (C) the powder particles after deagglomeration and (D) surface detail. Please click here to view a larger version of this figure.

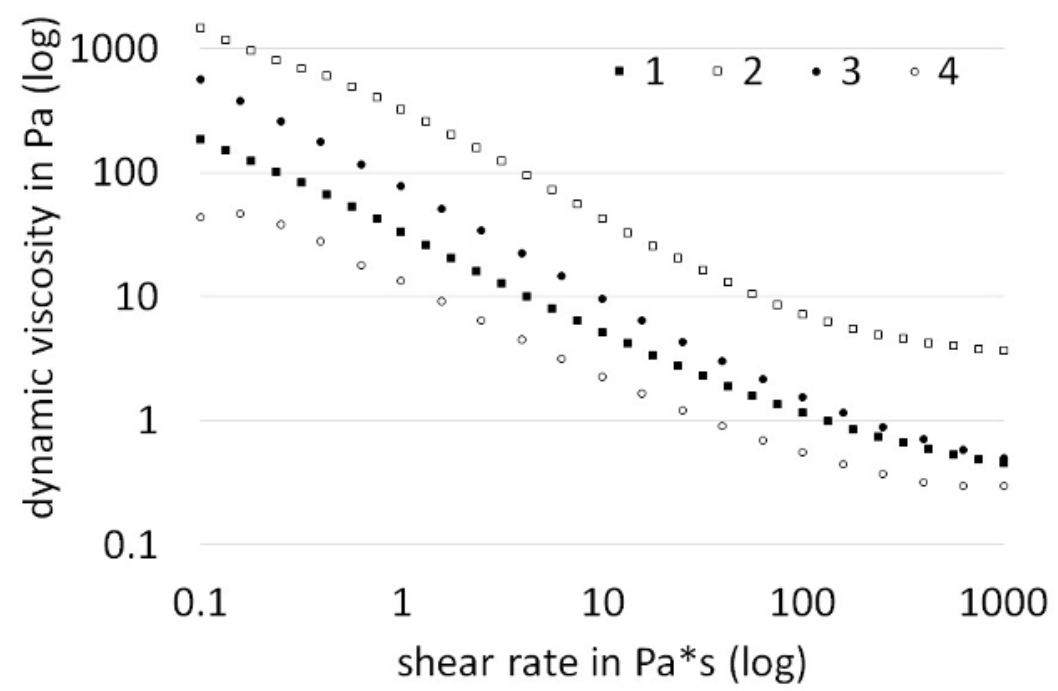

Figure 2: Dynamic viscosity as a function of the shear rate for different developed suspensions as depending on composition. Please click here to view a larger version of this figure. 


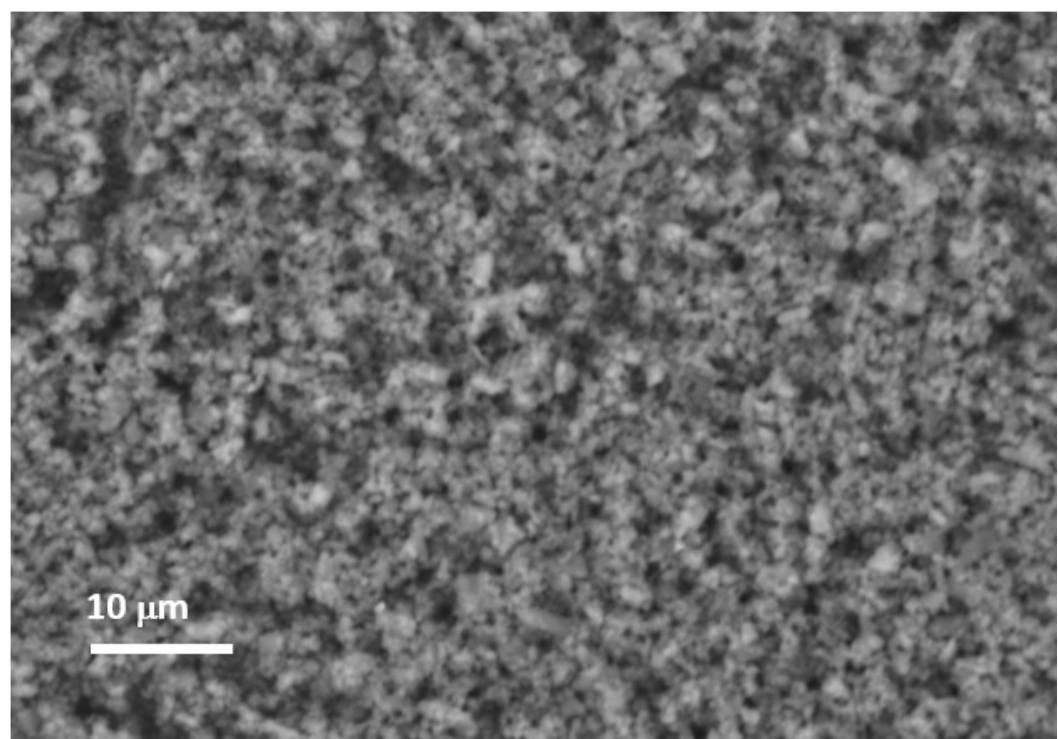

Figure 3: Field-emission scanning electron microscope image of a ceramic-resin suspension. The figure shows the powder suspension homogeneity on the polymeric resin.

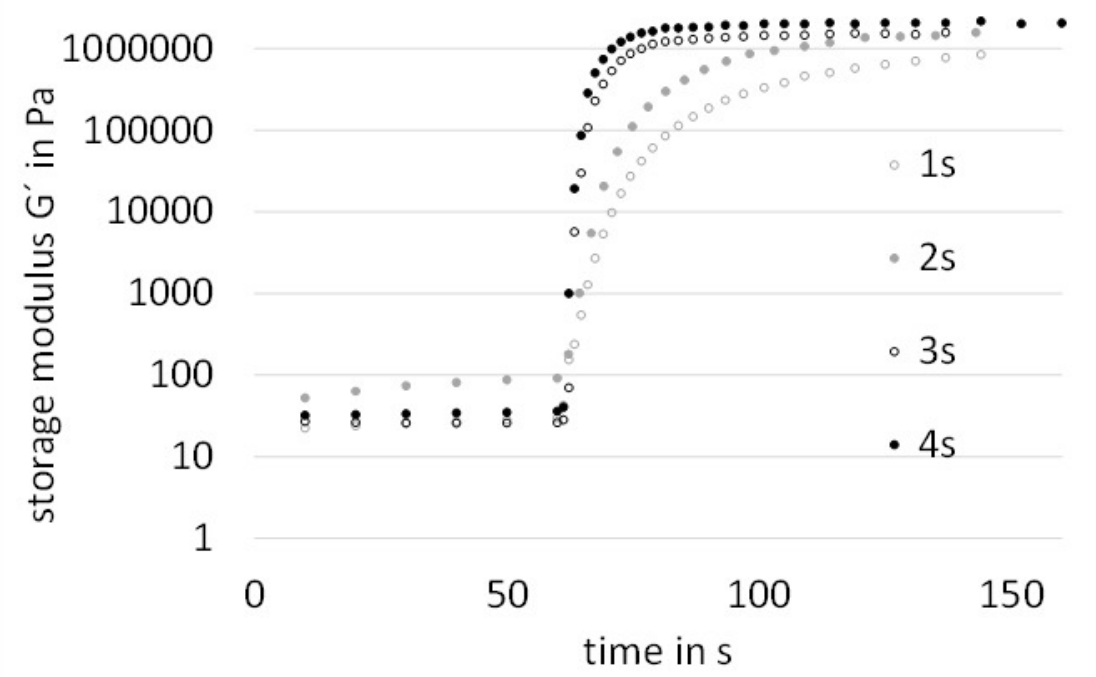

Figure 4: Storage modulus G' as a function of time for several suspensions with different compositions.

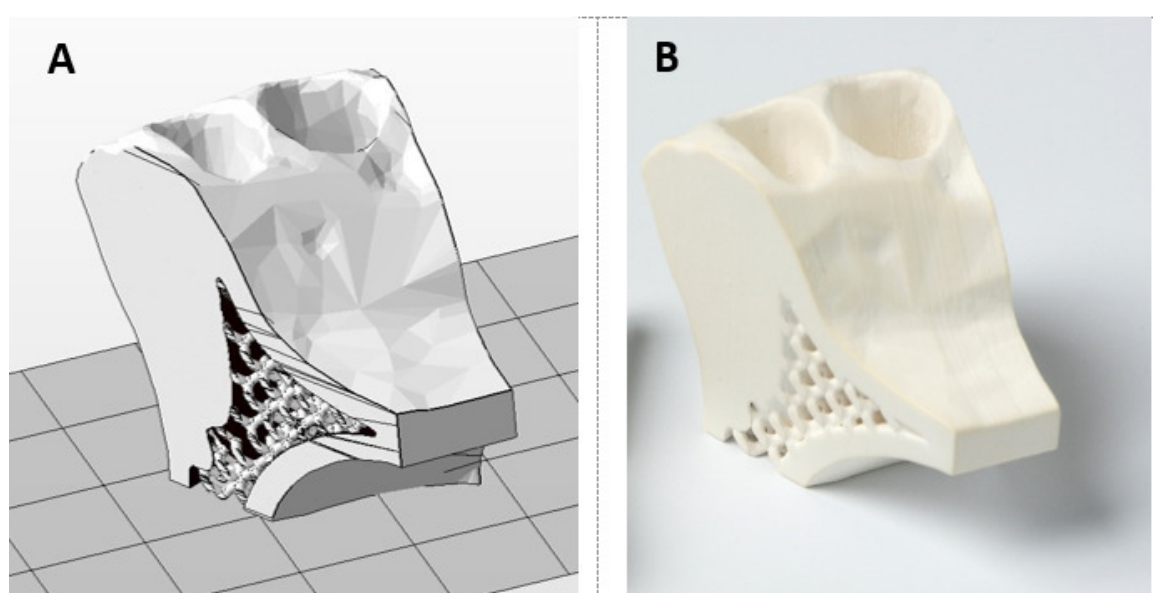

Figure 5: 3-D Modeling and Printing. (A) This panel shows a 3-D model of a single-material functionally graded ceramic material component. (B) This panel shows the sintered result of the printing process. 


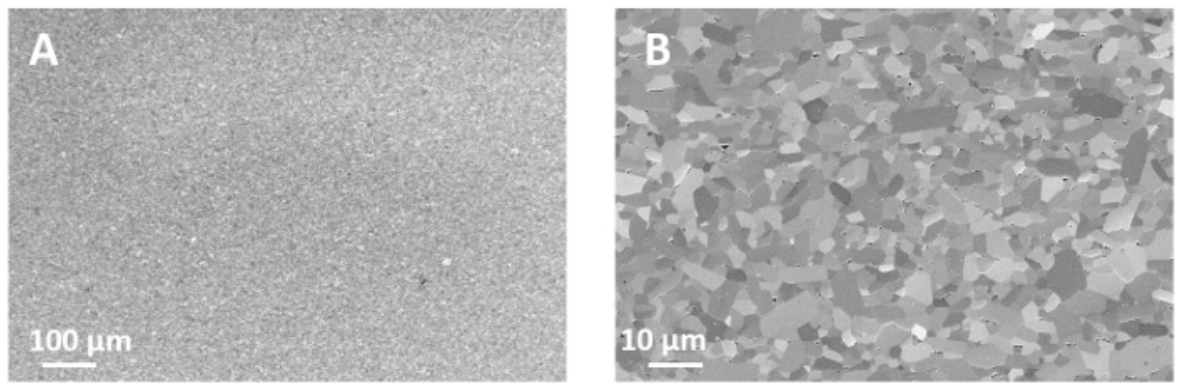

Figure 6: Field-emission scanning electron microscope images of a sintered alumina structure. (A) This panel shows an overview. (B) This panel shows a detailed image. Please click here to view a larger version of this figure.

\section{Discussion}

For medical implants, the raw material has to be of high purity, ideally of $99.9 \%$ and higher. In this project, a non-commercial alumina powder with a narrow particle size distribution, an average particle size $<0.5 \mu \mathrm{m}$, and a specific surface of approximately $7 \mathrm{~m}^{2} / \mathrm{g}$ is used. Alternatively, it is also possible to use commercial material compositions.

In order to achieve the most appropriate handling conditions for these particular ceramic-polymer slurries, use the aforementioned printing technology. This technology is equipped with a transport foil system that carries the slurry from a reservoir to the printing area. The printing area is composed of a transparent glass surface at the bottom, under which there is a light source that projects the sliced layers. At the top of the printing area, there is a building platform that can move vertically up and down thanks to a z-axis slide. The product, then, hangs on the surface of the metal printing plate that can be attached by vacuum suction, above the printing area. The unused slurry is then collected by a wiper, reconditioned, and pumped back to the original reservoir, thus creating a closed circuit which allows researchers to reuse the slurry that was not consumed for the construction of the 3-D model. Different software parameters can be changed in order to adapt the process to different slurry compositions and ceramic fillers. The printer must be placed in a room with controlled light, temperature, and humidity settings. The room must be equipped with a UV-filter for the outside light; in addition, it is recommended to have a temperature of around $20-24{ }^{\circ} \mathrm{C}$ and a relative humidity below $40 \%$. The FESEM imaging shows an apparent larger average particle size of alumina powder after deagglomeration, compared to the theoretical $0.45-\mu \mathrm{m}$ alumina material analyses by the supplier. This can be explained in terms of agglomeration. During drying, after the deagglomeration step, the particles re-agglomerate, as seen in Figure 1D. During the suspension preparation, the re-agglomerated particles can be dispersed thanks to the surface functionalization step. A smaller apparent particle size can be seen in the FESEM imaging of the slurry in Figure 3.

Concerning the rheological behavior, an ideal slurry for ceramic SLA technology (e.g., Admaflex technology) should have a shear thinning behavior (i.e., decreasing dynamic viscosity at higher shear rates). For an optimal cast on supporting foil or use within a dispensing unit, the dynamic viscosity should be kept at an ideal range at low shear rates. In case of too high dynamic viscosity at low shear rates, the casting of a slurry layer of $200 \mu \mathrm{m}$ might be hampered by the lack of flow to fill the gap under the doctor blade. If the dynamic viscosity it is too low, the suspension may flow by itself from the reservoir below the blade or away from the support foil due to natural flow (gravity). For all investigated suspensions, the dynamic viscosity decreases with an increasing shear rate. The optimal suspension flow behavior is given by composition 1 (Figure 2). Different changes in the slurry composition affect the rheological behavior of the suspension. The optimal flow behavior with a low dynamic viscosity in the required range was achieved by suspension compound 1 . An increase of the powder content or a non-optimal content of the dispersing agent (compound 2) and a change of the binder-crosslinker ratio using a higher amount of multifunctional crosslinker (composition 3 ) led to an increase of the dynamic viscosity, disadvantageously for the process. If the powder content is lower, together with a lower content of multifunctional crosslinker and in combination with a non-optimal content of the dispersing agent (composition 4), the dynamic viscosity is strongly reduced, possibly leading to an unstable suspension.

The change in storage modulus $G^{\prime}$ of the slurries upon light irradiation can help to learn more about the curing behavior of the suspensions. This is complemented by experimental tests on the depth of curing at the printing device itself. The curing behavior at different curing times was characterized for an alumina suspension with an optimal rheological behavior. Before curing starts, the suspension shows a low level of $\mathrm{G}^{\prime}$ and presents values below $100 \mathrm{~Pa}$. When curing starts, a polymerization of the photoreactive organics can be inferred by an increase of $\mathrm{G}$ ' to a higher level. With an increasing curing time, the slope of $\mathrm{G}^{\prime}$ increases to a maximum in a range of $10^{5}$ to $10^{7} \mathrm{~Pa}$ wich depends on the composition. A curing time of $1 \mathrm{~s}$ led to a final $\mathrm{G}^{\prime}$ below $10^{6} \mathrm{~Pa}$, which is not enough for a minimum necessary strength. With an increasing curing time, more energy (photons) is supplied to the suspension, which leads to a higher ' $\mathrm{G}^{\prime}$ as a result of a faster and higher degree of conversion (higher slope). The optimal curing time for the developed alumina suspension should be in a range of 2 to $3 \mathrm{~s}$. With a curing time of $4 \mathrm{~s}$, the final level of $\mathrm{G}^{\prime}$ and the curing slope have large values, above $2 \times 10^{6} \mathrm{~Pa}$. The conversion is almost complete and nearly no uncured polymers exist. Further energy supply may result in overcuring the slurry and an excessive hardening of the polymer, resulting in a brittle structure which has an adverse effect on the attachment of the product with the building platform.

The single-FGM test component chosen for this manuscript is a hemi-maxillary implant structure that contains a dense outer shell and a porous bone-like central core, as can be seen in Figure $\mathbf{5}$. This model could be additively manufactured and sintered defect-free, as seen by the FESEM imaging. Fine structures and wall thicknesses (less than $0.1 \mathrm{~mm}$ ) can be realized and no apparent deformation during sintering occurred. It was found that the microstructure of the single alumina components is typical for the ceramic processing of alumina at the given sintering temperatures, with a homogeneous grain size. The porosity in the bulk areas is very low (<1\%), and a density $>99 \%$, compared to the theoretical density, was achieved. 


\section{Disclosures}

The authors have nothing to disclose.

\section{Acknowledgments}

This project has received funding from the European Union's Horizon 2020 Research and Innovation Program under Grant Agreement No 678503.

\section{References}

1. Scheithauer, U. et al. Micro-reactors made by Lithography-based Ceramic Manufacturing (LCM). Ceramic Transactions. 258 (2016).

2. Scheithauer, U., Schwarzer, E., Moritz, T., Michaelis, A. Additive Manufacturing of Ceramic Heat Exchanger: Opportunities and Limits of the Lithography-Based Ceramic Manufacturing (LCM). Journal of Materials Engineering and Performance. 27 (1), 14-20 (2018).

3. Homa, J. Rapid Prototyping of high-performance ceramics opens new opportunities for the CIM industry. Powder Injection Molding International. 6 (3), 65-68 (2012).

4. Chartier, T., Badev, A. Rapid Prototyping of Ceramics. In Handbook of Advanced Ceramics Elsevier. Edited by Somiya, S., 489-524, Academic Press. Oxford, UK (2013).

5. Travitzky, N. et al. Additive Manufacturing of ceramic-based materials. Advanced Engineering Materials. 16, 729-754 (2014).

6. Hull, C. W. Apparatus for production of three-dimensional objects by stereolithography. US4575330A (1986).

7. Wätjen, A. M., Gingter, P., Kramer, M., Telle, R. Novel Prospects and Possibilities in Additive Manufacturing of Ceramics by means of Direct Inkjet Printing. Advances in Mechanical Engineering. 6 (2015).

8. Scheithauer, U., Schwarzer, E., Richter, H. J., Moritz, T. Thermoplastic 3-D Printing - An Additive Manufacturing Method for Producing Dense Ceramics. Journal of Applied and Computational Topology. 12 (1), 26-31 (2014).

9. Scheithauer, U. et al. Ceramic-Based 4D Components: Additive Manufacturing (AM) of Ceramic-Based Functionally Graded Materials (FGM) by Thermoplastic 3-D Printing (T3DP). Materials. (Basel). 10 (12), E1368 (2017).

10. Weingarten, S. et al. Multi-material ceramic-based components - Additive Manufacturing of black-and-white zirconia components by Thermoplastic 3D-Printing. Journal of Visualized Experiments. (Pending Publication), e57538, In-press (2018).

11. Zocca, A., Colombo, P., Gomes, C. M., Günster, J. Additive Manufacturing of Ceramics: Issues, Potentialities, and Opportunities. Journal of the American Ceramic Society. 98 (7), 1983-2001 (2015).

12. Kieback, B., Neubrand, A., Riedel, H. Processing techniques for functionally graded materials. Materials Science and Engineering - $A$. 362 (1-2), 81-106 (2003).

13. Mortensen, A., Suresh, S. Functionally graded metals and metal-ceramic composites: Part 1 Processing. International Materials Reviews. 40 (6), 239-265 (1995).

14. Moya, J. S., Sánchez-Herencia, A. J., Requena, J., Moreno, R. Functionally gradient ceramics by sequential slip casting. Materials Letters. 14 (5), 333-335 (1992).

15. Moya, J. S., Sánchez-Herencia, J .A., Bartolomé, J. F., Tanimoto, T. Elastic modulus in rigid Al2O3/ZrO2 ceramic laminates. Scripta Materialia. 37 (7), 1095-1103 (1997).

16. Zschippang, E., Mannschatz, A., Klemm, H., Moritz, T., Martin, H.-P. Charakterisierung und Verarbeitung von $\mathrm{Si}_{3} \mathrm{~N}_{4}-\mathrm{SiC}_{-}-\mathrm{MoSi}_{2}-\mathrm{Kompositen} \mathrm{für}$ Heizleiteranwendungen. Keramische Zeitschrift. 05, 294-297 (2013).

17. Scheithauer, U., Haderk, K., Richter, H.-J., Petasch, U., Michaelis, A. Influence of the kind and amount of pore forming agents on the thermal shock behaviour of carbon-free refractory components produced by multilayer technology. Refractories Worldforum. 4 (1), 130-136 (2011).

18. Scheithauer, U. et al. Functionally Graded Materials Made by Water-Based Multilayer Technology. Refractories Worldforum. 8 (2), $95-101$ (2016).

19. Mannschatz, A. et al. Manufacturing of Two-colored Co-sintered Zirconia Components by Inmold-labelling and 2C-Injection Molding, cfi/Ber. Delta Kappa Gamma. 91 (8), E1-E5 (2014).

20. Scheithauer, U. et al. Ceramic-Based 4D Components: Additive Manufacturing (AM) of Ceramic-Based Functionally Graded Materials (FGM) by Thermoplastic 3-D Printing (T3DP). Materials. 10 (12), 1368 (2017).

21. Moritz, T. et al. Material- and process hybridization for multifunctional ceramic and glass components. Ceramic Applications. 5 (2), $66-71$ (2017). 